\title{
Public Organizations of Analysts
}

DOI: $10.1134 / \mathrm{S} 1061934811050212$

The best known nongovernmental national organizations are analytical chemistry societies, as, for example, in Spain, Japan, Romania, and some other countries, or, more often, corresponding divisions, sections, etc., of chemical societies (in the United States, Germany, Switzerland, and many others). In addition, there are some other organizations that are closely, even directly, related to analytical chemistry. These are societies on mass spectrometry, chromatography, spectroscopy, and other similar disciplines; such organizations are, for example, in the United States; in Russia, the All-Russia Society on Mass Spectrometry was organized not long ago.

It is known that, in Russia, the main organization is the Scientific Council on Analytical Chemistry of the Russian Academy of Sciences; though it differs from the other societies in statute (it is not elective; the members and heads of the council are appointed), the council actually fulfills the same functions as the societies.

As for the international organizations, these are numerous. The leading is the Division of Analytical Chemistry of the European Association for Chemical and Molecular Sciences (DAC EuCheMS), the Division of Analytical Chemistry of the International Union of Pure and Applied Chemistry (DAC IUPAC), and the corresponding group of the Federation of Asian Chemical Societies (FACS). These organizations regularly convene large international conferences (Euroanalysis by DAC EuCheMS; analytical sections at IUPAC congresses by DAC IUPAC; Asianalysis conferences by FACS).
Among the other international societies, I would like to note the European Society on Separation Sciences and the International Organization for Chemistry in Development (IOCD); the latter focuses mainly on African and other developing countries.

I would also like to mention permanent committees of serial international conferences, for example, on flow analysis; here are also groups organizing regional meetings (International Symposium on Instrumental Analysis, conferences of the countries of the Black Sea basin, etc.). The members of such groups, as a matter of principle, vary, but the core that maintains the traditions, keeps track of the sequence of places for holding conferences, etc., remains the same. To some extent, among such organizations are also the established editorial boards of some scientific journals.

Public organizations of analysts do very useful job, much favoring the development of analytical chemistry. First of all, there is, of course, the organization of conferences, short-term training courses, and workshops. In addition, there is sharing the experience of teaching and working out recommendations in this field. The adjustment of and elaboration of nomenclature are of significant importance. Some journals are published by societies or some societies publish journals in collaboration (for example, the journal Chemia Analityczna-Chemical Analysis). The spheres of interests of many public organizations also cover problems of metrology, preparation of manuscripts for publishing, and ethical problems. 